\title{
DYNAMICS OF CONTRACEPTIVE USE AMONG YOUNG WOMEN IN NEPAL
}

\begin{abstract}
Ramesh Babu Kafle*
This paper examines the dynamics of contraceptive use of currently married young women (age 15-24) in Nepal by analyzing the trends and differentials in contraceptive use, the changes in method mix and the determinants of contraceptive use by selected socioeconomic and demographic characteristics. The reasons of non-use of contraception are also assessed. Data from the three rounds of nationally representative Nepal Demographic and Health Survey (NDHS) 2001, 2006 and 2011 are used. Currently married women aged 15-24 are selected and included in analysis. Study sample constitute 2573, 2398 and 2552 eligible women in NDHS 2001, 2006 and 2011 respectively. Use of contraception among young couples is gradually increasing in almost all subgroups of population in Nepal, with narrowing differentials by education and economic condition of household. Tendency of starting contraceptives before having a child is also emerging. There is declining share of sterilization among youth indicating either a probable shifting in age at sterilization or more favour towards temporary methods. Injection has the highest share in all the three surveys. The share of long acting temporary methods (IUD and Implants) is quite small and almost same in all the three surveys. Couples still feel safe to start using contraceptives after having at least one son however, the differences are declining. Reasons for non-use like fear of side effects and opposition to use are sharply declining over time but that due to husband's absence is emerging as almost a sufficient reason for non-use of contraception among young married women in Nepal. The family planning program should focus on meeting the family planning needs of young couples of all strata of population with special thrust on those women whose husbands are currently in foreign country so that they would be able to avoid unintended pregnancy on their husband's come back.
\end{abstract}

Keywords: Young women, contraception and husband's absence.

\section{INTRODUCTION}

Reproductive choices made by young people have a vast impact on their health, schooling, employment prospects and overall transition to adulthood (Blanc et al., 2009). Therefore, contraceptive behaviour of young people has consequences not only for their subsequent reproductive behaviours but also for whole population dynamics. The growth and size of the world population in future largely depends upon the reproductive behaviour of the largest ever cohort of the young people (Blanc et al., 2009). In the context of declining marital fertility in developing world, contraceptive use by young people is therefore an important aspect.

Nepal is undergoing fertility decline and has a large share of young population now. Less transition has occurred in Nepal in terms of age at first birth, and some transitions are occurring in the length of birth intervals (Kafle, 2016). Peak fertility at early ages is still a characteristic feature

* Dr. Kafle is Reader at Centre for Population and Development (CPAD), Purbanchal University, Biratnagar, Nepal. 
(Kafle, 2016). Family planning program in Nepal is being implemented for some four decades with varying efforts. Contraceptive use was gradually increasing and unmet need was gradually declining, but both of them have stalled in the recent past (MoHP et al., 2012, 2007). Improvement in educational status, more exposure to media and increased mobility of people has made a considerable social change in Nepal. A large chunk of male youth in Nepal is labour migrant in foreign countries and the proportion of currently married women whose husband is not staying at home at the time of survey is increasing over the periods of Nepal Demographic and Health Survey (NDHS) (MoHP et al., 2012, 2007, 2002). In this context, it is desirable to have better understanding of the dynamics of contraceptive use among young couples in the changing social contexts in Nepal.

Various demographic and socioeconomic factors influence contraceptive use. Women's parity and number of sons have strong associations with contraceptive use in Nepal, India and Bangladesh even after controlling for socioeconomic and other factors, including education, employment, wealth, media exposure, women's participation in household decision making, and urban or rural residence (Jayaraman et al., 2009). Similarly, choice of modern method in Turkey depended on the sex composition of living children, and woman's education was a strong predictor of method use and method choice (Koc, 2000). Women with higher levels of education were more likely to be current users of contraception, mainly the IUD and traditional methods (Gereltuya et al., 2007). In Kenya, better-educated, urbanized groups were more likely to use contraception than their counterparts (Njogu, 1991).

In this background, this paper examines the dynamics of contraceptive use of currently married young women in Nepal. Trends in use and the changes in method mix are analyzed. Differentials in the use of contraceptives by selected socioeconomic and demographic characteristics are studied. Moreover, this paper presents a comparative picture of determinants of contraceptive use by young women and also compares reasons of non-use of contraception.

\section{MATERIAL AND METHODS}

Data from the three rounds of nationally representative Nepal Demographic and Health Survey (NDHS) 2001, 2006 and 2011 are used for analysis. From women's data file, currently married women aged 15-24 are selected and included in analysis. Study sample constitute 2,573; 2,398 and 2,552 eligible women in NDHS 2001, 2006 and 2011 respectively. All the surveys followed two stage stratified sampling. Sampling weights are applied in calculating proportions.

Use of contraception at the time of survey is taken as dependent variable, which is measured as proportion of currently married women using contraception in univariate and bivariate analysis. The same variable is measured as a dichotomous nominal variable stating whether a woman is using any contraceptive at the time of survey ( $\mathrm{Yes}=1$ and $\mathrm{No}=0$ ) in multivariate analysis. Logistic Regression is used to examine determinants of contraceptive use among young women. Based on the review of literatures, women's age, number of living children, number of living sons, experience of child loss, type of place of residence, women's education, household wealth, working status, religion, exposure to media, ecological region, development region and whether husband is staying at home at the time of survey are considered as explanatory variables in analysis. 


\section{RESULTS}

Frequency distribution of currently married women aged 15-24 by selected background characteristics in the three surveys 2001, 2006 and 2011 is presented in Table1. In all the three surveys, among total women aged 15-24, around one third are in age 15-19, two fifths have one child and more than two fifths have at least one son. Proportion of young women experiencing child loss has declined from 10 percent in 2001 to six percent in 2011. Shift in educational status is observed where, proportion attaining more than 10 years of education has increased from six to 20 percent during 2001-2011. Similarly, share of young women working in non-agricultural sector is increased from six to 14 percent during the same period. The proportion of young women reporting their husbands residing elsewhere at the time of survey is increased substantially from 29 percent in 2001 to 41 percent in 2011.

Table 1: Percent distribution of currently married women age 15-24 by selected background characteristics, NDHS 2001, 2006 and 2011

\begin{tabular}{|c|c|c|c|c|}
\hline \multirow{2}{*}{\multicolumn{2}{|c|}{ Characteristics }} & \multicolumn{3}{|c|}{ Percentage distribution in } \\
\hline & & 2001 & 2006 & 2011 \\
\hline \multirow[t]{2}{*}{ Age } & $15-19$ & 36.2 & 32.8 & 31.0 \\
\hline & $20-24$ & 63.8 & 67.2 & 69.0 \\
\hline \multirow[t]{3}{*}{ Number of living children } & 0 & 32.8 & 29.8 & 33.7 \\
\hline & 1 & 35.7 & 39.2 & 40.9 \\
\hline & $2+$ & 31.5 & 30.9 & 25.4 \\
\hline \multirow[t]{2}{*}{ Number of living sons } & 0 & 57.8 & 55.8 & 58.4 \\
\hline & $1+$ & 42.2 & 44.2 & 41.6 \\
\hline \multirow[t]{2}{*}{ Child loss experience } & No & 90.1 & 93.1 & 93.8 \\
\hline & Yes & 9.9 & 6.9 & 6.2 \\
\hline \multirow[t]{2}{*}{ Residence } & Urban & 8.0 & 13.7 & 9.9 \\
\hline & Rural & 92.0 & 86.3 & 90.1 \\
\hline \multirow[t]{3}{*}{ Ecological region } & Mountain & 6.4 & 7.5 & 6.7 \\
\hline & Hill & 40.2 & 39.1 & 37.4 \\
\hline & Terai & 53.4 & 53.5 & 55.9 \\
\hline \multirow[t]{5}{*}{ Development region } & Eastern & 20.7 & 22.3 & 22.8 \\
\hline & Central & 34.5 & 31.8 & 33.2 \\
\hline & Western & 19.6 & 19.8 & 20.2 \\
\hline & Mid-Western & 14.8 & 12.3 & 13.6 \\
\hline & Far-Western & 10.5 & 13.8 & 10.2 \\
\hline \multirow[t]{3}{*}{ Education } & No education & 59.1 & 41.6 & 27.5 \\
\hline & 1-9 years & 35.2 & 50.6 & 52.7 \\
\hline & $10+$ years & 5.7 & 7.7 & 19.8 \\
\hline \multirow[t]{5}{*}{ Household wealth index } & Poorest & 21.4 & 18.3 & 17.3 \\
\hline & Poorer & 20.6 & 20.9 & 20.9 \\
\hline & Middle & 20.6 & 22.5 & 24.4 \\
\hline & Richer & 20.8 & 20.7 & 23.1 \\
\hline & Richest & 16.7 & 17.6 & 14.3 \\
\hline
\end{tabular}


Table 1 continued

\begin{tabular}{|ll|r|r|r|}
\hline \multirow{2}{*}{ Characteristics } & \multicolumn{3}{c|}{ Percentage distribution in } \\
\cline { 3 - 4 } Work status & & 2001 & 2006 & 2011 \\
& Not working & 25.7 & 26.7 & 32.9 \\
\multirow{3}{*}{ Religion } & Agricultural & 68.2 & 65.2 & 53.0 \\
& Non-agricultural & 6.1 & 8.1 & 14.1 \\
\multirow{3}{*}{ Exposure to media } & Hindu & 86.8 & 86.3 & 84.8 \\
& Non-Hindu & 13.2 & 13.7 & 15.2 \\
Husband's residential status & Low & 48.7 & 28.9 & 34.8 \\
& High & 51.3 & 71.1 & 65.2 \\
& Living with wife & 70.6 & 64.4 & 59.0 \\
& Staying elsewhere & 29.4 & 35.6 & 41.0 \\
\hline Number of women & & 2,573 & 2,389 & 2,552 \\
\hline
\end{tabular}

Level of current users of any method of contraception increased from 19 percent to 26 percent from 2001 to 2006 and remained same for 2011 (Table2). Stagnancy in the level of contraceptive use that is observed for all women of reproductive use (MoHP et al., 2012) is reflected among young women. Young women use different methods of contraception. The pattern of contraceptive use by young women is somewhat changed during the study period. Clearly increasing proportion of pills and traditional method users is observed. Maximum couples use injection followed by condom. Pill is the next popular method among young women. It is to be noted that only less than one percent young women in 2001 and 2006, and less than two percent in 2011are using long acting temporary methods IUD and implant.

Table 2: Status of contraceptive use and the methods used by young women at the time of survey, NDHS 2001, 2006 and 2011

\begin{tabular}{|l|r|r|r|}
\hline \multirow{2}{*}{ Method used } & \multicolumn{3}{|c|}{ Percent of women in } \\
\cline { 2 - 4 } & 2001 & 2006 & \multicolumn{1}{|c|}{2011} \\
\hline Male sterilization & 1.1 & 0.9 & 0.6 \\
Female sterilization & 2.6 & 2.9 & 2.5 \\
Condom & 4.2 & 6.0 & 5.6 \\
Injections & 6.4 & 9.9 & 7.4 \\
Pills & 1.5 & 2.9 & 3.5 \\
Other modern methods ${ }^{\#}$ & 0.8 & 0.7 & 1.4 \\
Traditional methods & 2.7 & 2.6 & 5.0 \\
Using any method & 19.3 & 25.8 & 25.8 \\
\hline Number of women & 2,573 & 2,389 & 2,552 \\
\hline
\end{tabular}

\# other modern methods include IUD and Implants.

Share of different methods of contraception among users of any method is depicted in Figure1. The declining share of sterilization among youth is observed for the study period which indicates either a probable shifting in age at sterilization or more favour of temporary methods. Injection has the highest share of use in all the three surveys. It may be due to the availability of this method through program up to the lowest level of health service centre. The share of condom is next to 
that of injections and has remained almost constant; that of pills and traditional methods is quite substantial and increasing; and share of long acting temporary methods (IUD and Implants) is quite small and remained almost same in all the three surveys.

Figure 1: Share of different methods of contraception

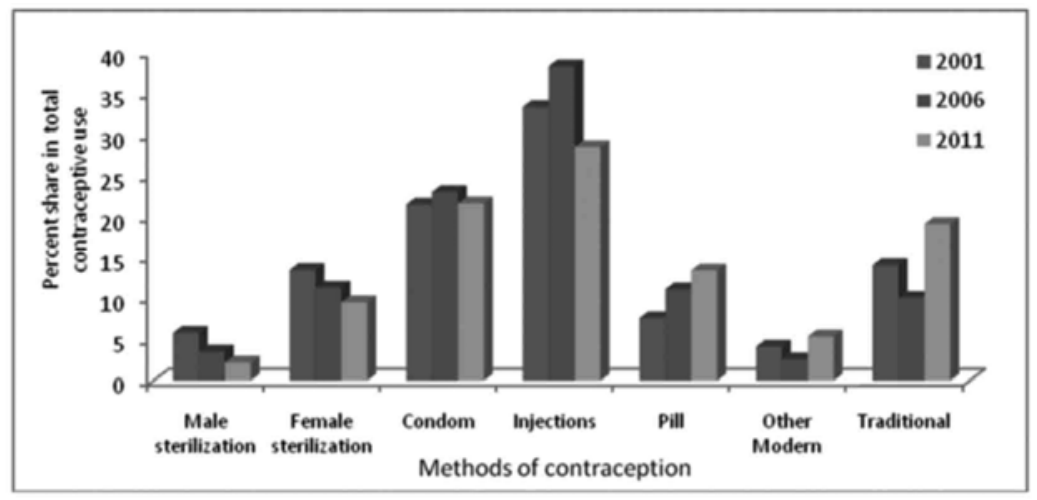

Differential in contraceptive use by various background characteristics is presented in Table3. The results show that there is only a little variation in contraceptive use among different ecological regions and development regions. A substantial variation in current use in all the three surveys is observed by age, number of living children and living sons, type of place of residence, women's education, work status, household wealth and exposure to media. Proportion of users is higher among women in age 20-24 as compared to those in age 15-19. Similarly, level of use is higher among women having at least two children and at least one son. Urban young women are better than rural young women in using contraception. A positive association between women's education and contraceptive use is observed, but the differentials are narrowing down over time. Moreover, the proportion of users among educated women is found to be declining over time. This may be due to the fact that these educated women have married at relatively higher age and prefer to catch up and have desired number of children soon. Women working in non-agriculture sector are better in contraceptive use as compared to their counterparts. Better household wealth status is associated with higher level of contraceptive use, but the differential is narrowing down over time. Positive association between media exposure and contraceptive use is also observed for all the three surveys.

Table 3: Percent of currently married women age 15-24 currently using any method of contraception by selected background characteristics, NDHS 2001, 2006 and 2011

\begin{tabular}{|ll|r|r|r|}
\hline \multirow{2}{*}{ Characteristics } & \multicolumn{3}{|c|}{ Percent using any contraception in } \\
\cline { 3 - 5 } & & 2001 & 2006 & \multicolumn{1}{c|}{2011} \\
\hline Age & $15-19$ & 11.9 & 15.9 & 17.6 \\
& $20-24$ & 23.4 & 30.6 & 29.5 \\
Number of living children & 0 & 7.2 & 8.6 & 11.6 \\
& 1 & 19.7 & 28.4 & 30.3 \\
\multirow{3}{*}{ Number of living sons } & $2+$ & 31.4 & 39.1 & 37.5 \\
& 0 & 11.6 & 18.5 & 18.6 \\
& $1+$ & 29.9 & 35.0 & 36.0 \\
\hline
\end{tabular}


Table 3 continued

\begin{tabular}{|c|c|c|c|c|}
\hline \multirow[t]{2}{*}{ Characteristics } & & \multicolumn{3}{|c|}{ Percent using any contraception in } \\
\hline & & 2001 & 2006 & 2011 \\
\hline \multirow[t]{2}{*}{ Child loss experience } & No & 19.6 & 26.3 & 26.1 \\
\hline & Yes & 16.8 & 18.8 & 21.5 \\
\hline \multirow[t]{2}{*}{ Residence } & Urban & 42.9 & 45.3 & 39.7 \\
\hline & Rural & 17.2 & 22.7 & 24.3 \\
\hline \multirow[t]{3}{*}{ Ecological region } & Mountain & 16.9 & 21.9 & 24.4 \\
\hline & Hill & 19.0 & 29.9 & 25.6 \\
\hline & Terai & 19.9 & 23.4 & 26.2 \\
\hline \multirow[t]{5}{*}{ Development region } & Eastern & 23.3 & 26.8 & 25.0 \\
\hline & Central & 19.8 & 28.3 & 27.6 \\
\hline & Western & 19.1 & 22.4 & 21.7 \\
\hline & Mid-Western & 17.3 & 23.5 & 25.1 \\
\hline & Far-Western & 13.0 & 25.5 & 31.0 \\
\hline \multirow[t]{3}{*}{ Education } & No education & 13.7 & 21.5 & 22.3 \\
\hline & $1-9$ years & 24.5 & 27.9 & 26.3 \\
\hline & $10+$ years & 45.2 & 35.7 & 29.7 \\
\hline \multirow[t]{5}{*}{ Household wealth index } & Poorest & 11.4 & 15.8 & 20.8 \\
\hline & Poorer & 12.5 & 20.6 & 23.8 \\
\hline & Middle & 15.9 & 22.0 & 23.0 \\
\hline & Richer & 21.5 & 29.2 & 28.7 \\
\hline & Richest & 39.4 & 43.1 & 35.3 \\
\hline \multirow[t]{3}{*}{ Work status } & Not working & 18.7 & 26.8 & 22.4 \\
\hline & Agricultural & 17.4 & 22.6 & 23.5 \\
\hline & Non-agricultural & 43.3 & 48.5 & 42.8 \\
\hline \multirow[t]{2}{*}{ Religion } & Hindu & 20.1 & 26.8 & 26.1 \\
\hline & Non-Hindu & 14.4 & 19.9 & 24.2 \\
\hline \multirow[t]{2}{*}{ Exposure to media } & Low & 12.1 & 18.4 & 23.7 \\
\hline & High & 26.1 & 28.9 & 27.0 \\
\hline \multirow[t]{2}{*}{ Husband's residential status } & Living with wife & 24.1 & 35.2 & 37.8 \\
\hline & Staying elsewhere & 7.8 & 8.8 & 8.6 \\
\hline All & & 19.3 & 25.8 & 25.8 \\
\hline
\end{tabular}

If husband is staying elsewhere, proportion of contraceptive users declines drastically. Only around eight percent women stated currently using contraception if their husbands were not staying at home at the time of survey. Proportion of users is increasing (24\% in 2001 to $38 \%$ in 2011) among women whose husband is living with wife at the time of survey. The stagnancy in level of contraceptive use among young women could be the result of increasing proportion of husband's absence, due to which they stop using it.

The results of multivariate analysis are shown in Table4. All the variables under study are included in the logistic regression model to see the net effect of each of the variables after controlling the effect of remaining variables. 
Table 4: Results of logistic regression showing odds ratios of contraceptive use for different categories of background characteristics

\begin{tabular}{|c|c|c|c|c|}
\hline \multirow[t]{2}{*}{ Characteristics } & & \multicolumn{3}{|c|}{ Odds ratio of using contraception } \\
\hline & & 2001 & 2006 & 2011 \\
\hline \multirow[t]{2}{*}{ Age } & $15-19$ & - & - & - \\
\hline & $20-24$ & 0.82 & 0.97 & 0.99 \\
\hline \multirow[t]{3}{*}{ Number of living children } & 0 & - & - & - \\
\hline & 1 & $2 . .45^{* * *}$ & $3.84^{* * *}$ & $3.25^{* * *}$ \\
\hline & $2+$ & $5.16^{* * *}$ & $6.97^{* * *}$ & $5.47^{* * *}$ \\
\hline \multirow[t]{2}{*}{ Number of living sons } & 0 & - & - & - \\
\hline & $1+$ & $2.21^{* * *}$ & $1.46^{* * *}$ & $1.44^{* * *}$ \\
\hline \multirow[t]{2}{*}{ Child loss experience } & No & - & - & - \\
\hline & Yes & 0.87 & $0.40^{* * *}$ & 0.74 \\
\hline \multirow[t]{2}{*}{ Residence } & Urban & - & - & - \\
\hline & Rural & 0.75 & $0.69^{* *}$ & $0.75^{*}$ \\
\hline \multirow[t]{3}{*}{ Ecological region } & Mountain & - & - & - \\
\hline & Hill & 1.03 & 0.94 & 1.08 \\
\hline & Terai & 1.24 & 0.72 & 1.21 \\
\hline \multirow[t]{5}{*}{ Development region } & Eastern & - & - & - \\
\hline & Central & 1.08 & 0.97 & 1.31 \\
\hline & Western & 0.78 & 0.85 & 0.98 \\
\hline & Mid-Western & 0.97 & 1.05 & 1.04 \\
\hline & Far-Western & $0.62^{*}$ & 1.13 & $1.45^{*}$ \\
\hline \multirow[t]{3}{*}{ Education } & No education & - & - & - \\
\hline & 1-9 years & $1.80^{* * *}$ & $1.33^{*}$ & $1.75^{* * *}$ \\
\hline & $10+$ years & $3.78^{* * *}$ & $2.01^{* *}$ & $2.06^{* * *}$ \\
\hline \multirow[t]{5}{*}{ Household wealth index } & Poorest & - & - & - \\
\hline & Poorer & 1.06 & $1.47^{*}$ & 1.33 \\
\hline & Middle & 1.44 & $1.81^{* *}$ & $1.45^{*}$ \\
\hline & Richer & $1.68^{* * *}$ & $2.08^{* * *}$ & 1.46 \\
\hline & Richest & $2.56^{* * *}$ & $2.59^{* * *}$ & $1.72^{*}$ \\
\hline \multirow[t]{3}{*}{ Work status } & Not working & - & - & - \\
\hline & Agricultural & $1.58^{* *}$ & 1.16 & $1.35^{*}$ \\
\hline & Non-agricultural & $2.20^{* * *}$ & $1.99^{* *}$ & $2.28^{* * *}$ \\
\hline \multirow[t]{2}{*}{ Religion } & Hindu & - & - & - \\
\hline & Non-Hindu & 0.75 & 0.85 & 0.99 \\
\hline \multirow[t]{2}{*}{ Exposure to media } & Low & - & - & - \\
\hline & High & $1.48^{* *}$ & $1.55^{* * *}$ & 1.18 \\
\hline \multirow[t]{2}{*}{ Husband's residential status } & Living with wife & - & - & - \\
\hline & Living elsewhere & $0.28^{* * *}$ & $0.13^{* * *}$ & $0.12^{* * *}$ \\
\hline \multirow{4}{*}{\multicolumn{2}{|c|}{$\begin{array}{l}\text { Constant } \\
-2 \text { Log Likelihood } \\
\text { Cox and Snell R }{ }^{2} \\
\text { Negelkerke } \mathrm{R}^{2}\end{array}$}} & $0.03^{* * *}$ & $0.07^{* * *}$ & $0.06^{* * *}$ \\
\hline & & 2022.48 & 2120.41 & 2264.00 \\
\hline & & 0.19 & 0.23 & 0.22 \\
\hline & & 0.30 & 0.34 & 0.32 \\
\hline \multicolumn{2}{|l|}{$\begin{array}{l}\text { Number of } \\
\text { (unweighted) }\end{array}$} & 2,535 & 2,429 & 2,438 \\
\hline
\end{tabular}


In all the three rounds of survey, the determinants of contraceptive use among young women are almost the same. It is observed that women with more living children, with at least one son, having better education, belonging to relatively better household wealth and working in non-agriculture sector have significantly higher odds of using contraception. Exposure to mass media has lost its significance in explaining the variation in contraceptive use among women over time and women's household wealth status is also losing its strength in explaining the differentials in contraceptive use among young women. After controlling for other factors, a positive association of women's education and household wealth condition with contraceptive use is found. Similarly, urban residence is also associated with higher odds of contraceptive use. Very low and significant odds of using contraception among women whose husband is staying elsewhere as compared to those whose husbands are living with them are observed. Both the role of socioeconomic and demographic factors and that of husband's residential status are evident from multivariate analysis.

After having analyzed the determinants of contraceptive use, some reasons of non-use are also assessed. Table5 shows the reasons of non-use of contraception among the non-users. Proportions of women not using contraception due to reasons related to opposition to use, fear of side effects, lack of knowledge of source and lack of access to the source are declining over time. Infrequent/no sex mainly due to husband's absence at home is cited as the most prominent reason of non-use of contraception and its extent is increasing.

Table 5: Reasons of non-use of contraception among non-users

\begin{tabular}{|l|r|r|r|}
\hline \multirow{2}{*}{ Reason of non-use } & \multicolumn{3}{|c|}{ Percent stating the reason in } \\
\cline { 2 - 4 } & 2001 & 2006 & 2011 \\
\hline No/Infrequentsex & 33.6 & 57.9 & 10.2 \\
Husband away & - & - & 58.4 \\
No/Infrequent sex or Husband away & - & - & 66.8 \\
PPA or Breastfeeding & 47.0 & 38.9 & 23.6 \\
Opposition to use* & 11.8 & 5.6 & 6.2 \\
Fear of side effects & 18.7 & 8.3 & 4.7 \\
Knows no source & 4.9 & 0.5 & 0.2 \\
Lack of access/too far & 3.6 & 2.0 & 0.3 \\
\hline
\end{tabular}

* Includes at least one of opposition by self, husband, others and religious opposition.

\section{DISCUSSION AND CONCLUSION}

Use of contraception among young couples is gradually increasing in almost all subgroups of population in Nepal. Regional variations are almost non-existent except for some urban rural differential which still favours urban women. Using contraceptives after having at least two children is consistently the most popular contraceptive behaviour of young women. However, tendency of starting contraceptives after birth of one child and before having the first birth is also emerging. This indicates couple’s enhanced capability of planning a family over time.

Due to higher preference for sons, couples feel safe to start using contraceptives after having at least one son. The educational differences in contraceptive use are declining over time and the same is true for having son. Economic differentials are also being narrowed down over time. Husband's absence from home is one of the powerful predictors of non-use of contraception 
among young women in Nepal. It has an independent effect on contraceptive use after controlling for other socioeconomic and demographic factors. However, factors like women's education, work and household economic condition are also significant predictors of contraceptive use of young women.

According to Njogu (1991), contraception would be adopted initially by older, high-parity women in order to cease childbearing, but, over time, use permeates even to those who want to prolong birth spacing. Results among young women in Nepal also indicate the similar pattern. A decline in the share of sterilization (both male and female) and increase in the share of other temporary methods indicates strengthening of births spacing motive of contraceptive use over time. According to Khan and Rahman (1996), educational status of women inBangladesh is associated with the differences in method choice by which, pills, condoms, and traditional methods were used more by the educated women, whereas injectables and the permanent methods were used more by the uneducated women. The shift in contraceptive use towards pills and traditional methods among young women in Nepal may also be due to change in educational status of women.

Reasons of non-use like fear of side effects and opposition to use are sharply declining but that due to husband's absence at home is emerging. Husband's absence at home is almost a sufficient condition of non-use of contraception among young married women in Nepal. This may be justifiable due to their infrequent or no sexual activity which reduces perceived chance of getting pregnant. But, the family planning program should consider these women as special group which is more vulnerable to unwanted pregnancy on their husband's come back either for a short duration or permanently mainly because of their lack of advance preparedness to avoid it. Program should have special thrust on those women whose husbands are migrants to ensure that they would be able to avoid unintended pregnancy after their husband's come back. Moreover, the program should consider very low level of use of long acting temporary methods among young women and channelize its service so as to enhance use of such methods which are more effective.

\section{Acknowledgements}

The author duly acknowledges Prof. P M Kulkarni and other participants for their comments during the presentation of earlier version of this paper in the National Seminar on Population and Health in the Context of Sustainable Development Goals held in Bhubaneshwar, India in January 2017.

\section{REFERENCES}

Blanc, A.K., Tsui, A.O., Croft, T.N., \& Trevitt, J.L. (2009). Patterns and trends in adolescents' contraceptive use and discontinuation in developing countries and comparisons with adult women. International Perspectives on Sexual and Reproductive Health, 35(2),63-71.

Gereltuya, A., Falkingham, J.,\& Brown, J. (2007). Determinants of current contraceptive use and method choice in Mongolia. Journal of Biosocial Sciences, 39, 801-817.

Jayaraman, A., Mishra, V.,\& Arnold, F. (2009). The relationship of family size and composition to fertility desires, contraceptive adoption and method choice in South Asia. International Perspectives on Sexual and Reproductive Health, 35(1), 29-38. 
Kafle, R.B. (2016). Fertility transition in a low income country: The case of Nepal. Unpublished Ph.D. thesis submitted to Centre for the Study of Regional Development, Jawaharlal Nehru University. New Delhi: Jawaharlal Nehru University.

Khan, M.A.,\& Rahman, M. (1996). Determinants of contraceptive method-choice in rural Bangladesh. International Centre for Diarrhoeal Disease Research (ICDDR) working paper No. 54. Dhaka: Centre for Health and Population Research.

Koc, I. (2000). Determinants of contraceptive use and method choice in Turkey. Journal of Biosocial Sciences, 32, 329-342.

Ministry of Health and Population (MoHP) [Nepal], New ERA, \& ICF International Inc. (2012). Nepal demographic and health survey 2011. Kathmandu, Nepal\& Calverton, Maryland: MoHP, New ERA, and ICF International.

Ministry of Health and Population (MoHP) [Nepal], New ERA, \& Macro International Inc. (2007). Nepal demographic and health survey 2006. Kathmandu, Nepal: MoHP, New ERA, and Macro International Inc.

Ministry of Health (MoH) [Nepal], New ERA, \& ORC Macro. (2002). Nepal demographic and health survey 2001. Calverton, Maryland, USA: MoH, New ERA,\& ORC Macro. 